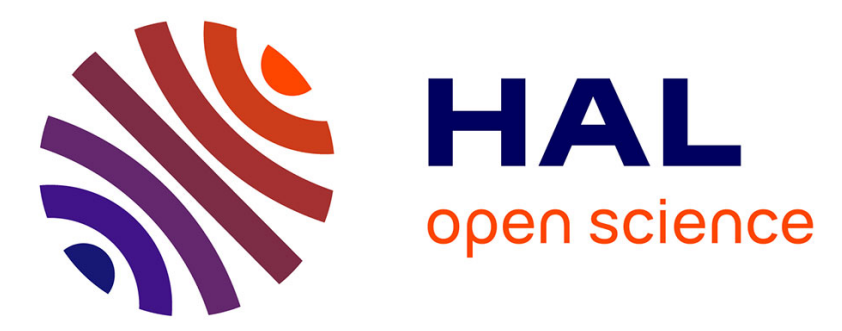

\title{
Kinetic study of the oxidation by oxygen of a zirconium based alloy: ZrNbO. Differences between the pre- and post-transition stages
}

Marc Tupin, Françoise Valdivieso, Michèle Pijolat, Michel Soustelle, Alain Frichet, Pierre Barberis

\section{To cite this version:}

Marc Tupin, Françoise Valdivieso, Michèle Pijolat, Michel Soustelle, Alain Frichet, et al.. Kinetic study of the oxidation by oxygen of a zirconium based alloy: ZrNbO. Differences between the preand post-transition stages. High temperature corrosion and protection of materials 6., May 2004, Les Embiez, France. pp.13-20. hal-00409932

\section{HAL Id: hal-00409932 https://hal.science/hal-00409932}

Submitted on 14 Aug 2009

HAL is a multi-disciplinary open access archive for the deposit and dissemination of scientific research documents, whether they are published or not. The documents may come from teaching and research institutions in France or abroad, or from public or private research centers.
L'archive ouverte pluridisciplinaire HAL, est destinée au dépôt et à la diffusion de documents scientifiques de niveau recherche, publiés ou non, émanant des établissements d'enseignement et de recherche français ou étrangers, des laboratoires publics ou privés. 


\section{Kinetic study of the oxidation by oxygen of a zirconium based alloy: ZrNbO. Differences between the pre- and post-transition stages}

\section{MARC TUPIN(1), FRANÇOISE VALDIVIESO ${ }^{(1)}$, MICHĖLE PIJ OLAT ${ }^{\left({ }^{*}\right)}$, MICHEL SOUSTELLE(1), ALAIN FRICHET( ${ }^{(2)}$, PIERRE BARBERIS(3).}

(1) Ecole Nationale Supérieure des Mines, Centre SPIN, Département ProcESS, LPMG, UMR CNRS 5148, 158 Cours Fauriel, 42023 SAINT-ETIENNE, Cedex 2, France

(2) FRAMATOME-ANP, 10 rue Juliette Récamier, 69456 LYON, Cedex 06, France.

(3) CEZUS, Centre de Recherches, 73043 Ugine cedex, France.

(3) mpijolat@emse.fr

Keywords:

zirconium alloys ; oxidation kinetics ; rate-limiting step ; oxygen pressure

\section{Abstract.}

The oxidation by oxygen of a zirconium based alloy, M5 ${ }^{\mathrm{TM}}$ (which is a $\mathrm{ZrNbO}$ alloy, containing $1 \%$ of $\mathrm{Nb}$ ) has been studied. The M5TM alloy, like many zirconium alloys, undergoes a kinetic transition. The aim of the present work is to achieve a better understanding of the oxidation in the pre-transition stage, and to clearly identify the differences between the pre- and post transition stages from the kinetic point of view.

The oxidation of $\mathrm{M}^{\mathrm{TM}}$ was followed by isothermal gravimetry at $490^{\circ} \mathrm{C}$, under a controlled partial pressure of oxygen (in the range 7 to $200 \mathrm{hPa}$ ). First, we have verified the steady state assumption, by coupling thermogravimetry and differential scanning calorimetry (DSC) : it is shown that the system is in a steady state from the beginning of the oxidation, in the pre- and post-transition stages. Then, the existence of a rate-limiting step was verified in the pretransition stage using an experimental method based on temperature or pressure jumps; this assumption is no more verified in the post-transition stage, which means that the oxidation does not proceed in the same way as in the pre-transition stage.

Finally, we have obtained the variations of zirconia growth reactivity $\Phi$ with the oxygen pressure, in the pre-transition stage (using the pressure jump method). The oxygen pressure has a slightly accelerating effect, which cannot be interpreted by the diffusion of oxygen vacancies through a dense oxide layer (in that case no effect of the oxygen pressure would be observed). In the post-transition stage, the oxygen effect is more important.

\section{Introduction}

Zirconium based alloys (and particularly Zircaloy-4) are widely used as cladding material of fuel rods in water-cooled nuclear reactors. However, advanced alloys are now used for longer operation time in more severe conditions. One of these new alloys, the M5 ${ }^{\mathrm{TM}}$ alloy developed by Framatome ANP, is a $\mathrm{ZrNbO}$, which contains $1 \%$ of $\mathrm{Nb}$ as alloying element.

Zirconium alloys usually undergo a kinetic transition, which is an increase in the oxidation rate when the oxide thickness exceeds a critical value. Nevertheless, the transition in M5 ${ }^{\mathrm{TM}}$ is not so sharp as in Zircaloys [1-3] (and in some cases it is not clearly observed). In the pretransition stage, the kinetic curves of oxidation are approximately parabolic (which is generally interpreted by a diffusion controlled step), and tend towards a quasi-linear behaviour after the transition. Some studies have shown that the oxygen pressure has an accelerating effect on the oxidation rate of $\mathrm{M}^{\mathrm{TM}}[2,4]$; a platinum layer deposited on the 
oxide surface has the same effect [5]. Thus it has been suggested that the oxidation in the pretransition stage could be described by a mixed reaction-diffusion kinetics [2, 3, 5]. The aim of the present work is to achieve a better understanding of the oxidation of M5 ${ }^{\mathrm{TM}}$ in oxygen, in the pre-transition stage (does the oxidation proceed in the steady state? Is there a ratelimiting step?), and to clearly identify the differences between the pre- and post transition stages from the kinetic point of view.

Consequently, we propose in this paper an approach principally based on the verification of the kinetic assumptions that are usually used a priori. The mechanism of oxide scale growth is assumed to consist in a series of elementary steps; one of them is supposed to be rate controlling, the others being at equilibrium. This assumption implies that (i) the system is in a steady state and (ii) that the oxidation rate can be expressed by Eq. 1[6]:

$$
\frac{d \xi}{d t}=n_{0} \Phi . E
$$

where $\xi$ is the oxide amount, $\mathrm{n}_{0}$ is the initial amount in metal, $\Phi$ is named the reactivity of growth of the oxide (it is a rate per unit of surface area, in mol.s $\mathrm{s}^{-1} \cdot \mathrm{m}^{-2}$ ), which depends on $\mathrm{T}, \mathrm{P}_{\mathrm{i}}$ (partial pressures), $a_{i}$ (activities of alloying elements), and $E$ is a function (in $\mathrm{m}^{2} \cdot \mathrm{mol}^{-1}$ ) characteristic of the extent of the reaction zone where the rate-limiting step occurs (it may depend on time, sample shape, ...). For example, in the case of a reaction limited by the diffusion of a chemical species in the oxide scale due to a concentration gradient, $\Phi$ and $E$ take the following expressions, for a plate having an initial thickness $2 \mathrm{x}_{0}$ and an area $\mathrm{s}_{0}$ :

$$
\Phi=\frac{D \cdot \Delta C}{x_{0}} \text { and } \mathrm{E}=\frac{2 \mathrm{x}_{0} \mathrm{~s}_{0}}{\mathrm{x} \mathrm{n}_{0}}=\frac{V_{M}}{x}
$$

where $\mathrm{D}$ is the diffusion coefficient, $\Delta \mathrm{C}$ the difference in concentrations of the diffusing species at the two interfaces, $\mathrm{x}$ the thickness of the growing oxide, $\mathrm{V}_{\mathrm{M}}$ the molar volume of the metal.

In this paper, the two assumptions (i) and (ii) will be verified experimentally in pre and post-transition stages, which is necessary before going further in the kinetic modelling of the oxidation. Then the variations of the zirconia growth reactivity $\Phi$ with the oxygen pressure will be obtained, using a method based on pressure jumps.

\section{Experimental results}

\section{Experimental.}

A $0.4 \mathrm{~mm}$ thick sheet of M5TM alloy was provided by Cezus, and samples were cut to $10 \times 10$ $\mathrm{mm}$ for thermogravimetric experiments. The alloy composition is indicated in Table 1 . The sample surface was cleaned with an equimolar solution of ethanol and acetone in an ultrasonic bath, then with pure ethanol and dried with compressed air.

\begin{tabular}{|c|c|c|}
\hline $\begin{array}{c}\mathrm{Fe} \\
{[\mathrm{ppm}]}\end{array}$ & $\begin{array}{c}\mathrm{O}_{2} \\
{[\mathrm{ppm}]}\end{array}$ & $\mathrm{Nb}(\%)$ \\
\hline 354 & 1303 & 1.03 \\
\hline
\end{tabular}

Table 1: Composition of the M5 ${ }^{\mathrm{TM}}$ alloy

The oxidation curves were obtained in isothermal and isobaric conditions at 490 and $520^{\circ} \mathrm{C}$ with a symmetrical thermoanalyser SETARAM MTB $10^{-8}$, the partial pressure of oxygen being in the range 7 to $200 \mathrm{hPa}$.

The experiments of simultaneous calorimetry and thermogravimetry were performed using a Setaram TG-DSC 111, under a flowing mixture of helium and oxygen.

The morphology of the oxide layers was observed by scanning electron microscopy (SEM DSM 960A Zeiss). 
$6^{\text {th }}$ International Symposium on High-Temperature Corrosion and Protection of Materials, Les Embiez, 16 au 21 mai 2004

\section{Shape of the kinetic curves.}

Fig. la represents a kinetic curve giving the mass gain $\mathrm{m}(\mathrm{t})$ versus time, and its derivative $\left(\mathrm{dm} / \mathrm{dt}\right.$ ), obtained at $520^{\circ} \mathrm{C}$ (after an initial temperature rise of $30^{\circ} \mathrm{C} / \mathrm{min}$ from room temperature to $520^{\circ} \mathrm{C}$ ), in $200 \mathrm{hPa}$ of oxygen.

Before the transition, the rate decreases continuously, the minimum rate corresponding to an oxide thickness (calculated from the weight gain) of about $9 \mu \mathrm{m}$. After the transition, the mass gain curve is more or less linear.

It can be noticed on the isobaric kinetic curves given in Fig. $1 \mathrm{~b}$ (for 13 and $200 \mathrm{hPa}$ of oxygen) that the oxygen pressure has an accelerating influence in the pre-transition stage, as observed in the literature $[2,4]$.

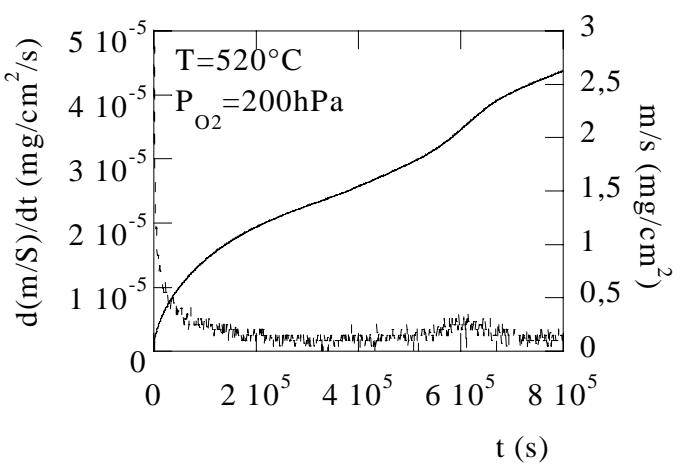

a

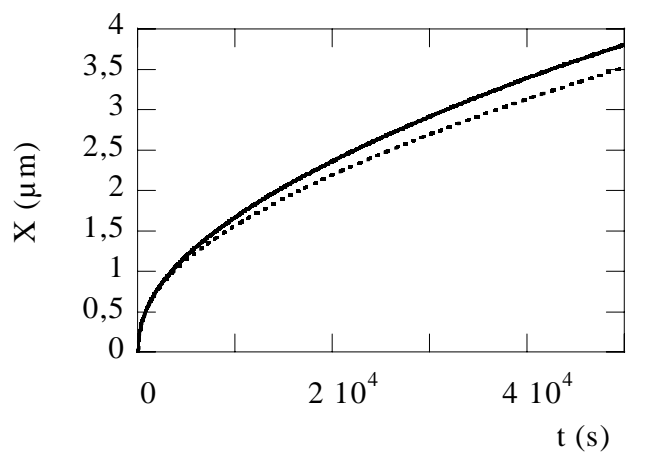

$\mathrm{b}$

Figure 1: (a) Weight gain and its derivative versus time for M5TM at $520^{\circ} \mathrm{C}(200 \mathrm{hPa}$ of oxygen), (b) thickness X versus time for $13 \mathrm{hPa}(---)$ and $200 \mathrm{hPa} \mathrm{(-)}$ of oxygen.

Steady-state assumption.

This assumption (i) can be verified using simultaneous thermogravimetry and differential scanning calorimetry (DSC) [7-9]. It can be shown easily [10] that when a system is in a steady state, the rates measured by two different experimental techniques should remain proportional at any time of the reaction. The rates of weight uptake and heat flow versus time are represented in Fig. $2 \mathrm{a}\left(550^{\circ} \mathrm{C}, \mathrm{P}_{\mathrm{O} 2}=100 \mathrm{hPa}\right)$, for both the pre and post-transition stages. Fig. $2 \mathrm{~b}$ represents only the pre-transition stage, showing that a scaling factor allowing to superimpose the rate curves can be found. In the post-transition stage (Fig.2c), a scaling factor can also be found, but it is not the same as before the transition.

From these results, the steady state assumption is definitely valid in the pre-transition stage; in the post-transition stage, the steady-state may be assumed, but the change in the scaling factor remains unexplained.

Rate-limiting step assumption.

The rate limiting step approximation means that the kinetics are controlled by the rate of one of the steps of the mechanism (elementary reactions like adsorption or interfacial reaction, and diffusion steps) and consequently the steady state is established. Then, Eq. 1 gives the variation of the rate with the time $(\mathrm{E}(\mathrm{t}))$ and the intensive variables (temperature, pressure,...). In isothermal and isobaric conditions, $\Phi(\mathrm{T}, \mathrm{P}, \ldots)$ is constant, therefore a sudden change in T or P during an experiment will lead to a change in $\Phi$ only, while $\mathrm{E}(\mathrm{t})$ will remain approximately the same before and after the change. It comes out that the ratio of the rate measured on the right side of the change $\left(\Phi_{\mathrm{r}}\right)$ to that measured on the left side $\left(\Phi_{1}\right)$ is simply equal to the ratio of $\frac{\Phi_{r}}{\Phi_{l}}$ according to Eq. 1. So by doing a series of sudden changes at different times of reaction, the ratio of the rates will be constant as long as Eq. 1, or the 
approximation of the rate limiting step, is valid. This method has been successfully used in previous work on various reaction systems [7-9, 11].

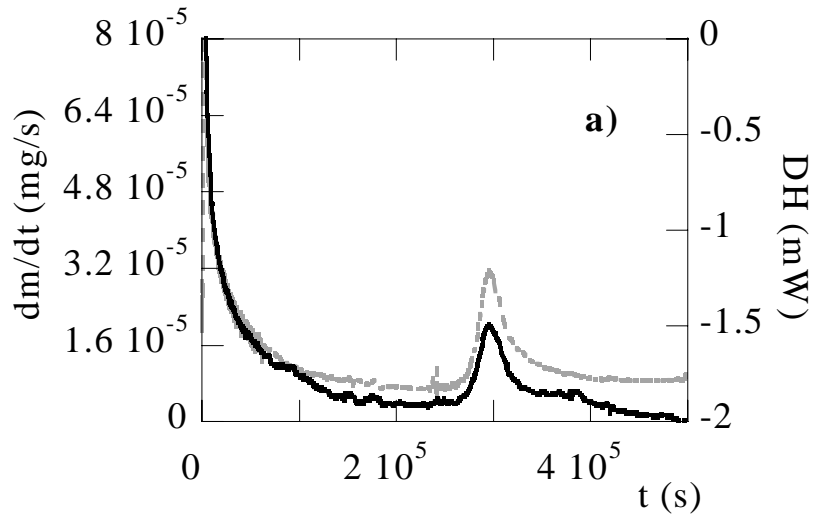

a

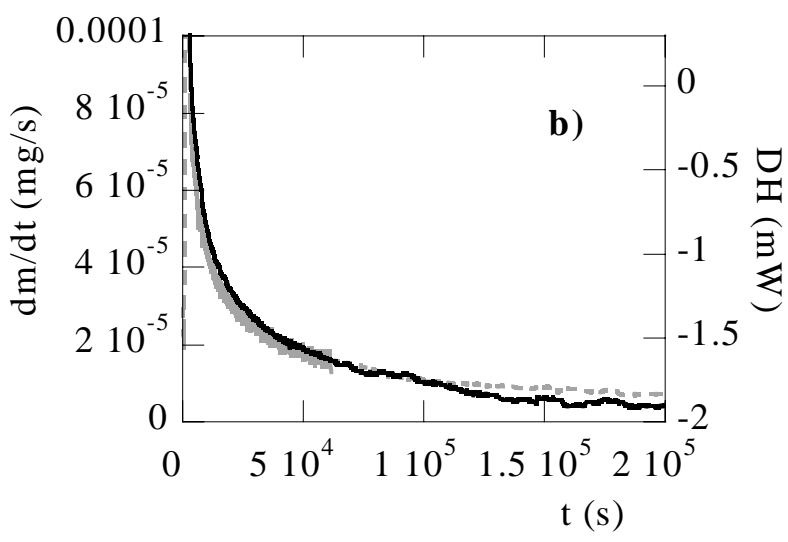

$\mathrm{b}$

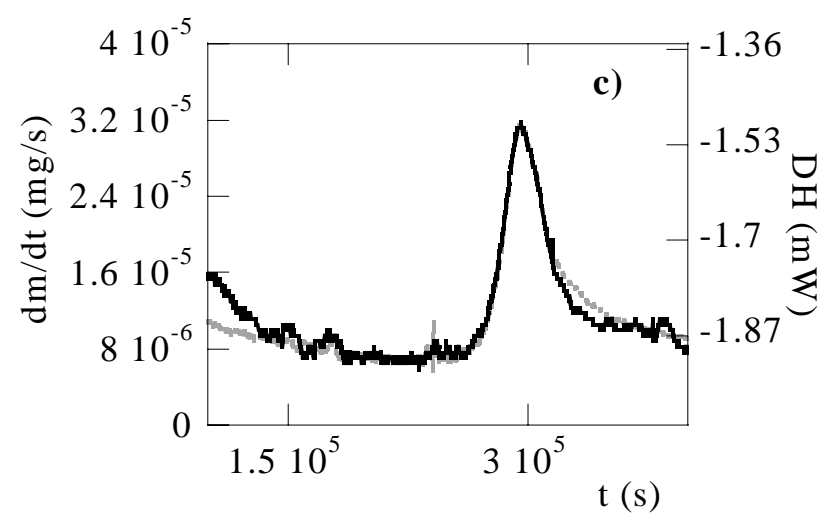

C

Figure 2: Rate of weight gain (---) and heat flow (-) versus time for $\mathrm{M} 5^{\mathrm{TM}}$ at $550^{\circ} \mathrm{C}$ in $100 \mathrm{hPa}$ of oxygen, pre- and post-transition stages (a), pre-transition stage (b), post-transition stage (c).

The result of this method, that we have called the « $\Phi$.E » test, is represented on Fig. 3, in the case of oxygen pressure jumps from 200 to $13 \mathrm{hPa}\left(\mathrm{T}=490^{\circ} \mathrm{C}(\mathrm{a})\right.$ or $\left.520^{\circ} \mathrm{C}(\mathrm{b})\right)$.

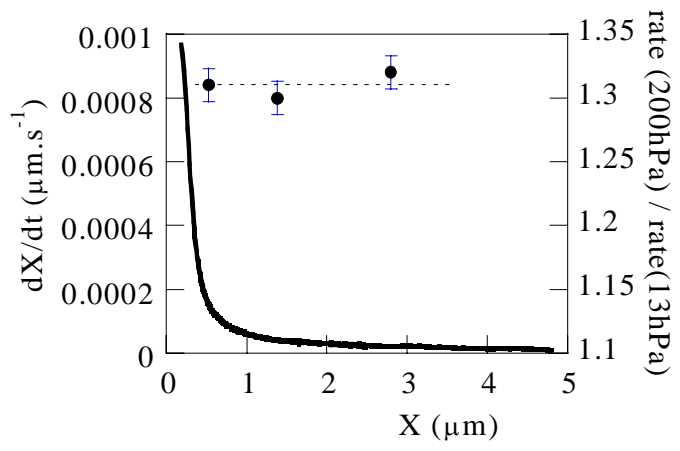

a

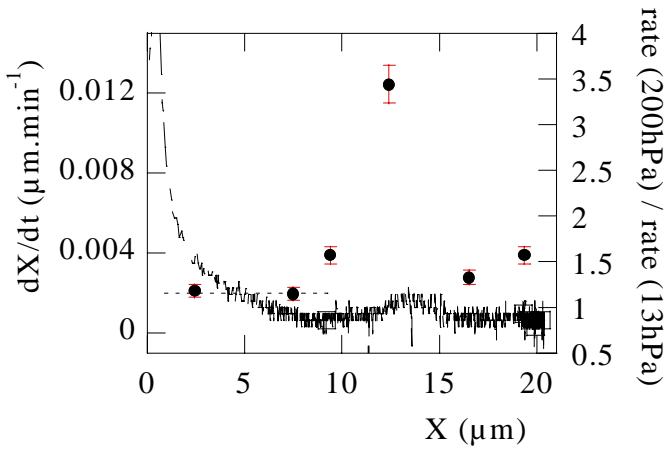

$\mathrm{b}$

Figure 3: Rate of weight gain and ratios of the rate before and after an oxygen pressure jump from 200 to $13 \mathrm{hPa}$, in the pre-transition stage $\left.\left(\mathrm{T}=490^{\circ} \mathrm{C}, \mathrm{a}\right)\right)$ and in the pre and post-transition stages $\left(\mathrm{T}=520^{\circ} \mathrm{C}, \mathrm{b}\right)$ ).

Considering the experimental error bars, the ratio keeps a constant value $(1.31 \pm 1 \%$ at $490^{\circ} \mathrm{C}, 1.16 \pm 1.7 \%$ at $520^{\circ} \mathrm{C}$ ) during the pre-transition stage up to about $8 \mu \mathrm{m}$ (Fig. 3a and 
3b). Then it increases (3.4 at $12.5 \mu \mathrm{m}$ ) and decreases again. Thus it can be concluded that the " $\Phi E$ test" is validated in the pre-transition domain only, it is not verified in the post-transition stage since the ratio of the rates is not constant with the extent of weight increase, therefore the rate limiting step approximation is not valid.

In order to confirm these results, another test has been performed, consisting of comparing two isothermal curves obtained at different temperatures (at the same oxygen pressure) : if the rate curves can be superimposed whatever the extent of the reaction (or the oxide thickness) is, the rates are proportional which means that they can be written as the product of two functions, one depending on the temperature (and partial pressures) and the other depending only on the thickness X. This test is usually called the "affinity test", the results are given in Fig. 4, for two isothermal (Fig. 4a) or isobaric experiments (Fig. 4b).

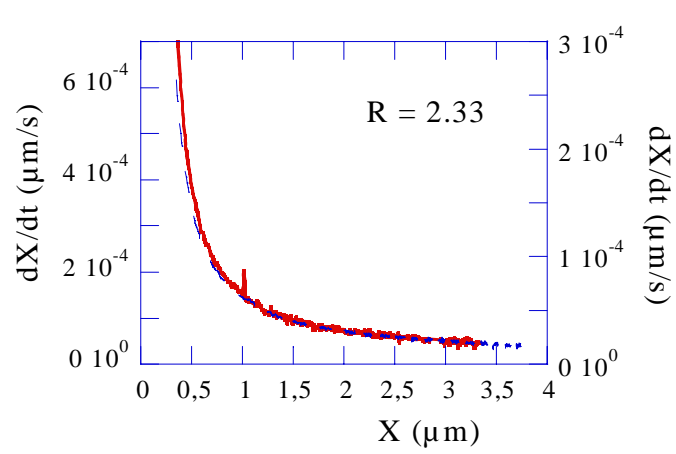

a

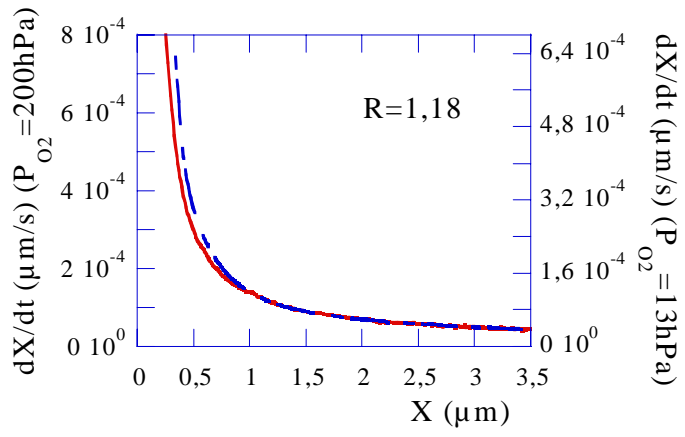

$\mathrm{b}$

Figure 4: Test of affinity for (a) isothermal curves $\left(\mathrm{T}=490\right.$ and $\left.520^{\circ} \mathrm{C}, \mathrm{P}_{\mathrm{O} 2}=200 \mathrm{hPa}\right)$ and (b) isobaric curves ( 13 and $200 \mathrm{hPa}, \mathrm{T}=520^{\circ} \mathrm{C}$ )

\section{Influence of the oxygen partial pressure.}

The experimental method to obtain the variations of $\Phi$ with the partial pressure of the reacting gases is also based on the sudden change method: in that case, several changes are carried out at a given weight gain, from a pressure $\mathrm{P}_{0}$ to various pressures $\mathrm{P}$ (the temperature being constant). The ratio of the rates before and after the change, equal to $\frac{\Phi(\mathrm{P})}{\Phi\left(\mathrm{P}_{0}\right)}$ according to Eq. 1, is proportional to the variations of $\Phi$ with $\mathrm{P},\left(\Phi\left(\mathrm{P}_{0}\right)\right.$ keeping the same value in all the experiments).

In the pre-transition stage, the experiments have been carried out at $490^{\circ} \mathrm{C}$, the oxygen pressure being changed (from $13 \mathrm{hPa}$ to a pressure $\mathrm{P}$ ) at a weight gain corresponding to an oxide thickness equal to $2.4 \mu \mathrm{m}$.

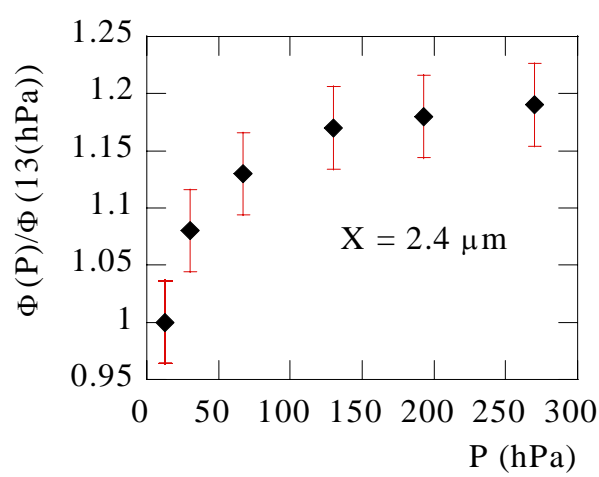

a

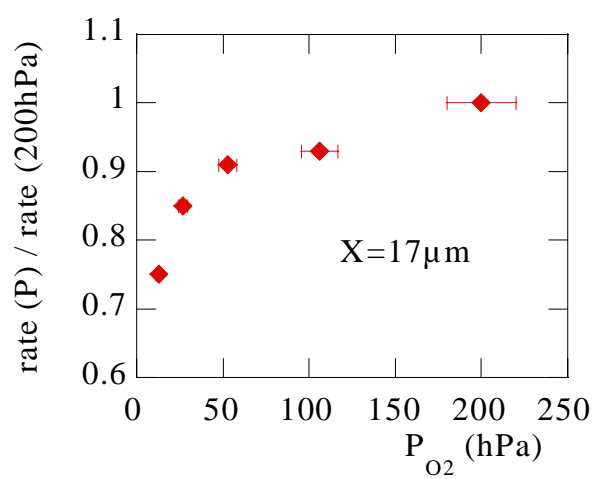

b

Figure 5: Ratios of weight gain rate before and after the oxygen pressure changes in pre-transition stage $\left(\mathrm{T}=490^{\circ} \mathrm{C}, \mathrm{X}=2.4 \mu \mathrm{m}\right)(\mathrm{a})$ and in post-transition stage $\left(\mathrm{T}=520^{\circ} \mathrm{C}, \mathrm{X}=17 \mu \mathrm{m}\right)(\mathrm{b})$. 
The results are given in Fig. 5a: the growth reactivity $\Phi$ increases slightly when the oxygen pressure increases.

In the post-transition stage, the experiments have been carried out at $520^{\circ} \mathrm{C}$, the sudden changes in oxygen pressure (from $200 \mathrm{hPa}$ to a pressure $\mathrm{P}$ ) being done at an oxide thickness of $17 \mu \mathrm{m}$. As in the pre-transition stage, the higher the oxygen pressure, the higher the oxidation rate (Fig. 5b).

\section{Characterisation of the samples.}

The cross-sectional views of the oxide scale grown during the pre-transition region present a continuous and uniform layer adherent to the substrate. Fig. 6a shows a micrograph obtained for a sample oxidised at $520^{\circ} \mathrm{C}$ in $200 \mathrm{hPa}$ of oxygen. The layer thickness calculated from the weight gain is $8 \mu \mathrm{m}$. No cracks connected to the gaseous atmosphere could be observed ; the interface is more or less regularly undulated. Short cracks parallel to the interface appear regularly inside the layer.

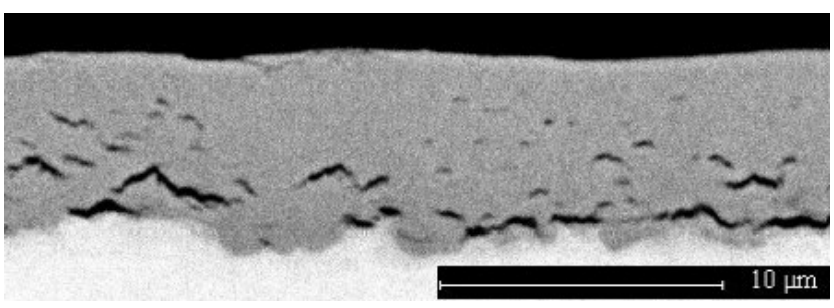

a

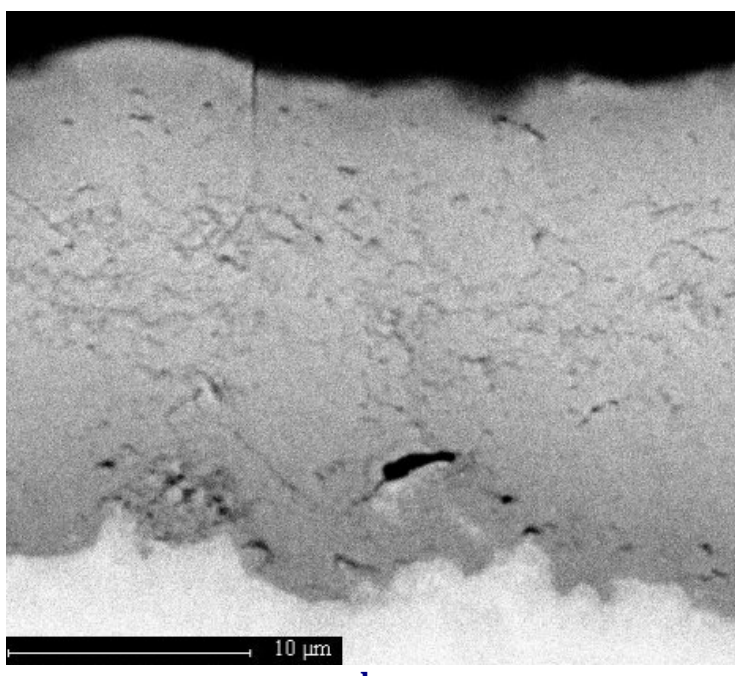

$\mathrm{b}$

Figure 6: Cross sectional views of $\mathrm{M}^{\mathrm{TM}}$ samples oxidised at $520^{\circ} \mathrm{C}\left(\mathrm{P}_{\mathrm{O} 2}=200 \mathrm{hPa}\right)$; in pre $(\mathrm{a})$ and post-transition stages (b).

Similar cracks exist in the samples obtained after the kinetic transition (Fig. 6b), but there are also a lot of very fine cracks, probably connected one to the other, and a few large cracks perpendicular to the interface and connected to the gaseous atmosphere. Due to all these cracks, the gaseous oxygen probably reaches more easily the metal/ oxide interface.

\section{Discussion.}

Pre-transition stage.

It has been shown that the assumptions of steady state and rate-limiting step are valid in the pre-transition stage. The zirconia growth can be simply described by the following mechanism:

Step 1: $\quad$ adsorption step on a surface site noted "s": $\mathrm{O}_{2}+2 s_{\rightarrow}^{\leftarrow} 2 \mathrm{O}-\mathrm{s}$

Step 2: $\quad$ external interface reaction step: $O-s+V_{O}^{\bullet \bullet}+2 e_{\rightarrow}^{\leftarrow} O_{O}+s$

Step 3: oxygen vacancies diffusion: $V_{O_{\text {int }}}^{\cdot \bullet}-->V_{O_{\text {ext }}}^{\bullet \bullet}$ and $O_{O_{\text {ext }}}^{x}-->O_{O_{\text {int }}}^{x}$ and electrons diffusion: $e_{\mathrm{int}}^{\prime}--->e_{e x t}^{\prime}$

Step 4: internal interface reaction step: $Z r_{Z r(\text { métal }) \rightarrow}{ }_{\rightarrow} r_{Z r}^{X}+2 V_{O}^{\bullet \bullet}+4 e^{\prime}$

A linear combination of the steps (1) to (4) ((1) $+2 \mathrm{x}(2)+(3)+(4))$ leads to the stoichiometric equation: 
$6^{\text {th }}$ International Symposium on High-Temperature Corrosion and Protection of Materials, Les Embiez, 16 au 21 mai 2004

$$
\mathrm{Zr}+\mathrm{O}_{2}=\mathrm{ZrO}_{2}
$$

Then, assuming that each of these steps can be rate-limiting, the expressions of the growth reactivity $\Phi$ can be calculated, as indicated in table 2 (in which $K_{i}(i=1,2$, or 4 ) represents the equilibrium constant of the $i^{\text {th }}$ elementary step, $\mathrm{k}_{\mathrm{i}}$ are the rate constants, and $\mathrm{K}_{\mathrm{O} 2}$ is the equilibrium constant corresponding to Eq. 3).

At $520^{\circ} \mathrm{C}, \mathrm{K}_{\mathrm{O} 2}$ is equal to $2.10^{62}$, which means that the term $1 / \mathrm{K}_{\mathrm{O}_{2}} P_{\mathrm{O}_{2}}$ in the expressions

of $\Phi$ can be neglected beside 1 . Thus, only a rate-limiting step located at the outer interface can account for the influence of oxygen pressure which is observed. But, if one of these steps was rate-limiting, the kinetic curves should be linear, which is obviously not the case.

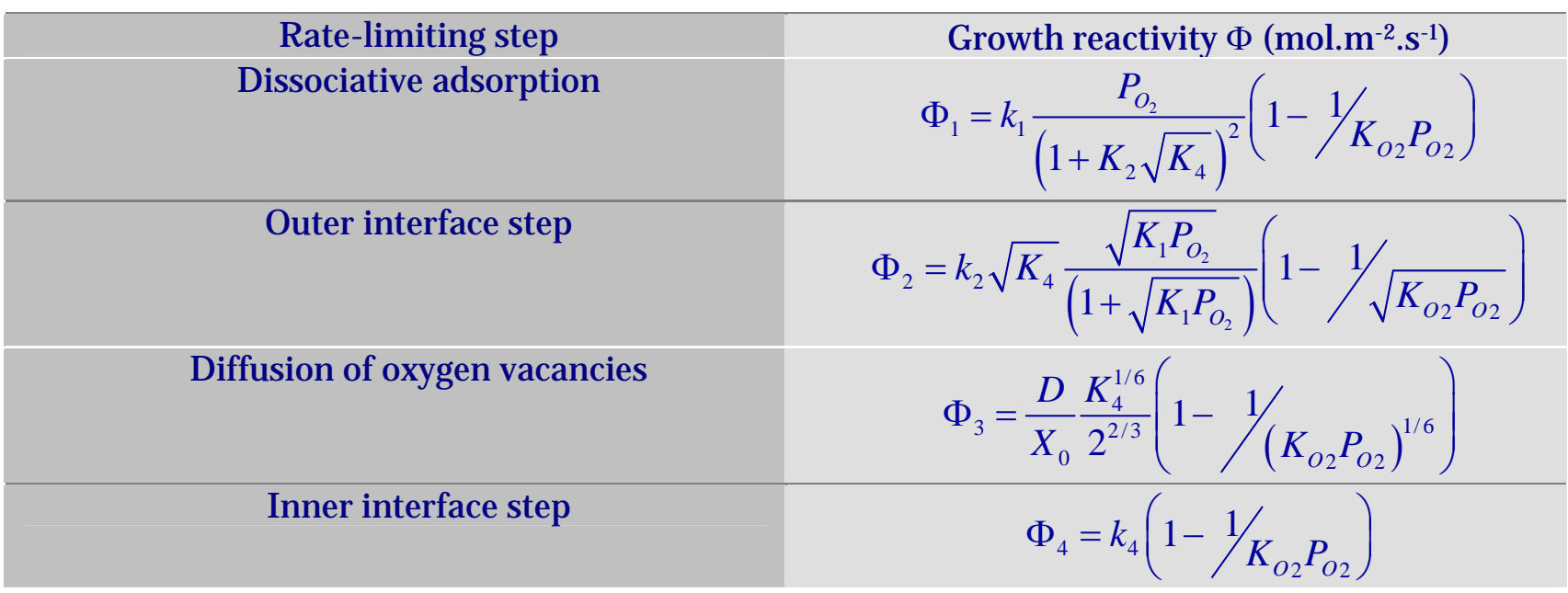

Table 2: Expressions of the growth reactivity $\Phi$ for the various rate-limiting steps.

Some authors $[2,3,5]$ have proposed that the oxide growth could be controlled by a mixed interface reaction-diffusion kinetics. But in that case, the " $\Phi E$ " test and the test of affinity would not be validated.

Finally, it appears that the mechanism described above can not explain all the experimental results.

However, the kinetic curves are characteristic of a diffusion controlled kinetics, and their sub-parabolic shape can be fitted by the following equation:

$$
\frac{d X}{d t}=\frac{k_{1}}{X} \exp \left(-k_{2} X\right)
$$

which has already been used for the oxidation of Zircaloy-4 [8, 9].

The effect of the oxygen pressure can be accounted for if the concentration of the diffusing species is controlled by an external interface step (and not an internal interface step as in the mechanism described above, in which the growth reactivity $\Phi$ depends only on the concentration of oxygen vacancies at the inner interface (their concentration at the outer interface being neglected due to the value of $\left.\mathrm{K}_{02}\right)$ ). A mechanism has been suggested [12], involving two layers, one porous and one dense, the diffusion of adsorbed oxygen species through the porous layer being rate-limiting. This mechanism is in agreement with the experimental results.

\section{Post-transition stage.}

It has been shown that after the transition, the reacting system remains in a steady state, but the "Ф.E" test is not validated, and the oxygen pressure has a greater effect than in pretransition. It is clear from these results that the rate-limiting step which controls the beginning of the oxidation is no longer valid after the transition. 
In the post-transition stage, it can be assumed that the zirconia growth is controlled by a mixed reaction-diffusion kinetics (since the "Ф.E" test is not validated). This is in agreement with the shape of the kinetic curves [12, 13], but the elementary steps involved in the oxidation rate have not been determined successively.

\section{Conclusions}

The oxidation of a $\mathrm{ZrNbO}$ alloy (M5T ${ }^{\mathrm{M}}$ alloy) has been studied between 500 and $530^{\circ} \mathrm{C}$, under controlled oxygen partial pressure. It has been shown that strong differences exist between the pre- and post-transition stages.

Although the system is in a steady state in both stages, the oxidation is controlled by a ratelimiting step (and not a mixed reaction-diffusion kinetics) in the pre-transition stage only. It has also been confirmed that the oxygen pressure has a slight accelerating influence on the oxidation.

Due to the sub-parabolic shape of the curves, this rate-limiting step is most probably a diffusion step; nevertheless, the mechanism proposed usually for zirconium oxidation (diffusion of oxygen vacancies in a dense layer) is not in agreement with the oxygen effect. This result can be explained if the concentration of the diffusing species is controlled by a step located at the outer interface [12].

After the transition, the assumption of the rate-limiting step is no longer valid, and the oxygen effect is more important. Consequently, it can be concluded that the rate in posttransition is not controlled by the same step as in the pre-transition stage.

\section{References}

[1] E. Hillner, Zirconium in the nuclear industry, ASTM STP 633, (1977), p.311.

[2] N. Petigny-Putigny, Thesis, Dijon (1998).

[3] B. Cox, J . Nucl. Mat., 148 (1987) p. 332.

[4] International Atomic Energy Agency, IAEA-TECDOC-996, Vienna (1998).

[5] Personal communication.

[6] M. Soustelle, M. Pijolat, Solid State Ionics Vol 95 (1997), p. 33.

[7] K. Surla, F. Valdivieso, M. Pijolat, M. Soustelle, M. Prin, Solid State Ionics Vol 143 (2001), p. 355.

[8] F. Ledoux, F. Valdivieso, M. Pijolat, M. Soustelle, A. Frichet, P. Barberis, Materials Science Forum Vol. 369 (1) (2001), p.223.

[9] M. Tupin, M. Pijolat, F. Valdivieso, M. Soustelle, A. Frichet, P. Barberis, J . Nucl. Mat. 317 (2003), p. 130.

[10] R. Lalauze, A. Souchon, M. Soustelle, Oxid. Metals Vol 10(2) (1976), p.105.

[11] J.P. Viricelle, M. Pijolat, M. Soustelle, J. Chem. Soc. Faraday Trans. Vol 91(24) (1995), p. 4437.

[12] M. Tupin, Thesis, Saint-Etienne (2002).

[13] M. Tupin, F. Valdivieso, M. Pijolat, M. Soustelle, A. Frichet, P. Barberis, these proceedings. 